\title{
Modeling Laminated Orthotropic Plate-Foundation Interaction Subjected to Moving Load Using Vlasov Model
}

\author{
Korhan ÖZGAN ${ }^{1}$
}

\begin{abstract}
In this study, dynamic behavior of laminated orthotropic plates on elastic foundation is investigated adapting the three-parameter subsoil model. Analysis of the system is performed by using the software SAP2000 combining with MATLAB code for calculation of soil parameters for modified Vlasov model. A computing tool is coded in MATLAB for the purpose, allowing data exchange between SAP2000 and MATLAB via Open Application Programming Interface (OAPI) feature. The consistency of the proposed model is shown by a numerical example taken from the literature. Subsequently, the effects of lamination scheme, various lamination angles, lamination number, subsoil depth, elasticity modulus of subsoil, plate thickness and the velocity of moving load on the behavior of laminated orthotropic plates on elastic foundation are investigated. It is concluded that it is a convenient approach to use OAPI feature of SAP2000 to model the complex behavior of laminated orthotropic plates on elastic soil, under moving loads.
\end{abstract}

Keywords: Moving load, elastic foundation, laminated orthotropic plate, OAPI.

\section{INTRODUCTION}

The analysis of engineering structures in contact with subsoil is still important today. Especially in recent years, rapid developments in the industry and use of composites in the sector caused an increase in the studies on soil-structure interaction. For years, the relationship between soil and structure is investigated by modeling as plate or beam on elastic foundation. Beams or plates on elastic foundation are used in many engineering areas such as aerospace industry, mechanical engineering, dentistry, liquid and gas transmission lines, aircraft hangars, airfields, highway and railway pavements. Railways, highways and airfield pavements are usually subjected to traversing moving loads such as wheel loads from moving vehicles and planes. It is therefore interesting and important for engineers to understand the dynamic behavior of the plates or beams on elastic foundations before their structural design.

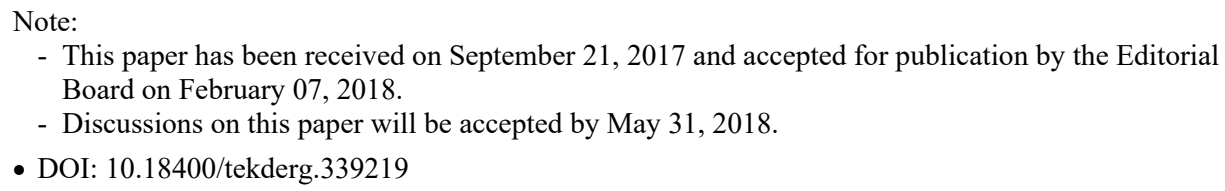

- This paper has been received on September 21, 2017 and accepted for publication by the Editorial Board on February 07, 2018.

- Discussions on this paper will be accepted by May 31, 2018.

- DOI: 10.18400/tekderg.339219

1 Karadeniz Technical University, Dep. of Civil Engineering, Trabzon, Turkey - korhanozgan@yahoo.com 
Modeling Laminated Orthotropic Plate-Foundation Interaction Subjected ...

Dynamic behavior of plates resting on elastic foundations subjected to moving loads has been studied by researchers for many years incorporating various types of soil models. Kim and Roesset [1] investigated the dynamic response of an infinite plate on Winkler-type elastic foundation subjected to constant amplitude or harmonic moving loads. Huang and Thambiratnam [2] developed a procedure incorporating the finite strip method and a spring system for the dynamic response of plate resting on an elastic foundation, subjected to moving loads. Kim [3] investigated the stability and dynamic displacement response of an infinite thin plate resting on a Winkler-type or a two parameter elastic foundation subjected to in-plane static compressive forces and a distributed moving load with a constant velocity. Lu et al. [4] examined vibration behavior of a plate on a two-parameter foundation subjected to moving rectangular loads of varying velocities.

On the other hand, composite materials are widely used in various fields of engineering like aerospace, naval, automotive and civil, owing to high strength or stiffness sections for lower weight using various fiber orientations and lamination schemes. Accordingly, studies on laminated orthotropic plates subjected to moving load had been carried out by many authors. Wang [5] developed a mixed finite element formulation based on the Mindlin-Reissner plate theory for a moving orthotropic thin plate. Zhu and Law [6] analyzed the dynamic behavior of an orthotropic plate under moving load using Lagrange equation and modal superposition. Alisjahbana [7] presented an approximate method for determination of the natural frequencies and mode shapes of rectangular clamped orthotropic plates subjected to dynamic moving loads. Lee and Yhim [8] performed dynamic analysis of single and two-span continuous composite plate structures subjected to multi-moving loads. Law et al. [9] investigated the problems of identification of moving loads on a three-dimensional bridge deck. Hatami et al. [10] studied free vibration of axially moving symmetrically laminated plates subjected to in-plan forces using the classical plate theory. Ghafoori and Asghari [11] investigated the dynamic response of angle-ply laminated composite plates traversed by a moving mass or a moving force. Malekzadeh et al. [12] presented a solution procedure based on the three-dimensional elasticity theory for the dynamic response of cross-ply laminated thick plates subjected to moving load. Thai et al. [13] investigated static, free vibration, and buckling behavior of laminated composite plates using the first-order shear deformation theory. Chen et al. [14] studied the dynamic instability of laminated composite plates under thermal and arbitrary in-plane periodic loads using first-order shear deformation plate theory. Patel [15] studied the geometric nonlinear bending behavior of laminated composite stiffened plates subjected to uniform transverse loading.

However, combination of laminated orthotropic material properties with subsoil effects at the same time in a study is very rarely found. Özçelikörs et al. [16] presented new functional and finite elements for interaction of orthotropic plate-foundation using the Gateaux differential and Pasternak type elastic foundation model. Pradhan and Kumar [17] studied vibration of orthotropic single layered graphene sheets embedded in Winkler-type and Pasternak-type elastic medium using nonlocal elasticity theory and differential quadrature method. Akgoz and Civalek [18] performed geometrically nonlinear free vibration analysis of thin laminated plates resting on non-linear elastic foundations. Vosoughi et al. [19] investigated dynamic response of moderately thick antisymmetric cross-ply laminated rectangular plates on Pasternak type elastic foundation using higher order shear deformation theory. Afsharmanesh et al. [20] solved buckling and vibration characteristics of circular laminated plates under in-plane edge loads and resting on Winkler-type foundation by the 
Ritz method. Mantari et al. [21] presented a free vibration analysis for functionally graded plates resting on Pasternak type elastic foundation using a quasi-3D hybrid type HSDT with 5 unknowns. Alipour [22] developed a new analytical approach for bending and stress analysis of angle-ply laminated composite and sandwich plates on non-uniform elastic foundation. Studies on laminated orthotropic plates on three parameter elastic foundation subjected to moving load have not been encountered yet in the literature.

As the first attempt, dynamic response of laminated orthotropic plates on elastic foundation under moving load is studied by using modified Vlasov foundation model. SAP2000 [23] software for the finite element analysis of soil-structure system with MATLAB [24] software for the calculation of soil parameters according to modified Vlasov model were used simultaneously. A computing tool was developed to provide two-way data exchange between SAP2000 and MATLAB by employing Open Application Programming Interface (OAPI) feature of SAP2000 software. Further, the effects of lamination scheme, various lamination angles, lamination number, subsoil depth, elasticity modulus of subsoil, plate thickness and velocity of moving load on the behavior of laminated orthotropic plates on elastic foundation were examined.

\section{SAP2000 OPEN APPLICATION PROGRAMMING INTERFACE}

With OAPI feature, the user is able to access SAP2000 by an external application with help of any supporting programming language such as Visual Basic, Microsoft Excel and MATLAB. It also allows users to build, analyze and design and to obtain analysis and design results. Structural model may be created via SAP2000 software. Any information for the structural model may be sent to SAP2000 with OAPI using a programming language. The desired features of SAP2000 may be accessed and performed for analysis or design. Analysis or design results of SAP2000 into any application may be transferred. In other words, finite element analysis is performed by SAP2000 and the results can be utilized by an external application [23].

In this study, SAP2000 was used interactively with a computing tool coded in MATLAB using OAPI functions for the analysis of laminated orthotropic plates on elastic foundation according to the modified Vlasov model.

\section{THEORETICAL FORMULATION AND FEM MODEL}

If modified Vlasov model is used to model soil structure interaction, the dynamic equation of the plate receiving vertical reaction of the subsoil into account without damping can be written as,

$$
D \nabla^{4} w(x, y, t)-2 t \nabla^{2} w(x, y, t)+k w(x, y, t)+m \frac{\partial^{2} w(x, y, t)}{\partial t^{2}}=p(x, y, t)
$$

where $w, m$ and $p$ denote vertical displacement of the plate, mass density and the magnitude moving load respectively. $k$ and $2 t$ depict subgrade reaction modulus and shear deformation 
Modeling Laminated Orthotropic Plate-Foundation Interaction Subjected ...

parameter of the subsoil. Value of $\gamma$ and $\beta$ coefficient for Newmark- $\beta$ method used for time integration of Eq.(1) are taken as 0.5 and 0.25 respectively [25].

If $P(x, y, t)$ is zero in Eq.(1), free vibration equation of a plate on elastic foundation is obtained.

Subsoil reactions of elastic foundation to a plate may be given by equation below depending on the displacement function $w$ of the subsoil surface when modified Vlasov model is considered.

$q_{z}=k w(x, y, t)-2 t\left(\frac{\partial^{2} w(x, y, t)}{\partial x^{2}}+\frac{\partial^{2} w(x, y, t)}{\partial y^{2}}\right)$

Subgrade reaction modulus $(k)$ and shear deformation parameter $(2 t)$ of subsoil for modified Vlasov model in above expression may be defined as

$k=\int_{0}^{H_{s}} \frac{E_{s}\left(1-v_{s}\right)}{\left(1+v_{s}\right)\left(1-2 v_{s}\right)}\left(\frac{\partial \varphi(z)}{\partial z}\right)^{2} d z$

$2 t=\int_{0}^{H_{s}} \frac{E_{s}}{2\left(1+v_{s}\right)} \varphi(z)^{2} d z$

where $H_{s}, E_{s}$ and $v_{\mathrm{s}}$ are depth, elasticity modulus and Poisson's ratio of the subsoil respectively.

If shear deformation parameter of subsoil, $2 t$, is taken as equal to zero, Eq.(1) returns to dynamic governing equation for plate on Winkler type elastic foundation. Although it is the most preferred and very easy to apply, Winkler model ignores interaction and shear deformation within the subsoil assuming subsoil under the plate to be independent, closely spaced, discrete and linearly elastic springs. In reality, soil is a continuous medium and this assumption is seen as a deficiency of the model. For elimination of the deficiency in the Winkler model, researchers have endeavored developing a new two-parameter foundation models such as Pasternak Model, Hetenyi Model and Vlasov model. But they failed to establish any relationship between the soil parameters and soil types. Vallabhan et al. [26] have focused on this problem and have introduced a new third parameter, $\gamma$, as a function of the vertical deformation profile within the subsoil to use for the calculation of soil parameters. The necessity to determine the values of soil parameters, $k$ and $2 t$, arbitrarily is eliminated by computing these values as a function of a new third parameter, $\gamma$, using an iterative procedure in their model called the modified Vlasov model.

The mode shape function, $\varphi(z)$, in Eq.3-4 describes the relationship between vertical displacement throughout subsoil and surface vertical displacement of plate. Mode shape function depends on the subsoil surface vertical deformation parameter, $\gamma$, and may be given as below, Fig.1. 
$\varphi(z)=\frac{\sinh \gamma\left(1-\frac{z}{H_{s}}\right)}{\sinh \gamma}$

where $\gamma$ is calculated using the equation shown below.

$\left(\frac{\gamma}{H_{s}}\right)^{2}=\frac{\left(1-2 v_{s}\right)}{2\left(1-v_{s}\right)} \frac{\int_{-\infty}^{+\infty} \int_{-\infty}^{+\infty}(\nabla w)^{2} d x d y}{\int_{-\infty}^{+\infty} \int_{-\infty}^{+\infty} w^{2} d x d y}$

As can be seen in Eq.(5) above, displacements of the plate must be known to calculate the $\gamma$ parameter. For this, the analysis of the soil-structure system must be performed. But it is necessary to know the values of soil parameters, $k$ and $2 t$ before the analysis, and soil parameters vary depending on mode shape function, $\varphi(z)$. At the same time, mode shape function is dependent on the vertical deformation parameter, $\gamma$. Therefore, the solution of this complex soil-structure interaction problem must be performed using an iterative technique.

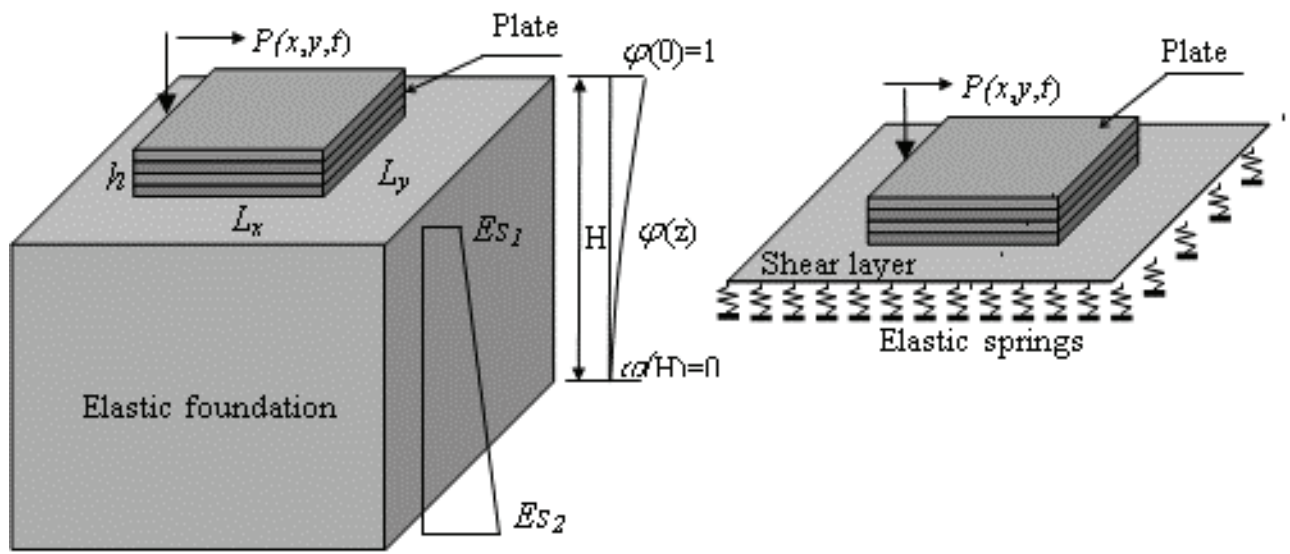

a) 3D plate on elastic subsoil

b) Mathematical model

Fig.1 A plate on three parameter elastic foundation

For the analysis of mathematical model shown in Fig.1(b), finite element model of the laminated orthotropic plate on elastic foundation is developed initially by the use of SAP2000 software. Plate is defined as an area element and the shear layer is defined as a shelllayered/nonlinear element with unit thickness. Elastic area springs are then assigned at the 
Modeling Laminated Orthotropic Plate-Foundation Interaction Subjected ...

bottom of the shell-layered/nonlinear element. After the finite element model is completed in SAP2000, a computing tool developed in MATLAB is used to allow two-way data flow with SAP2000 simultaneously. Soil parameters calculated in MATLAB are supplied as input data to SAP2000 via OAPI functions. Subsequently the structure-soil system is analyzed and the surface displacements of the foundation are sent to MATLAB code. Soil parameters are re-calculated. The process is repeated until the difference between the new value of $\gamma_{i+l}$ and the previously calculated $\gamma_{i}$ attains a prescribed tolerance. The flow chart for the solution is given in Fig.2.

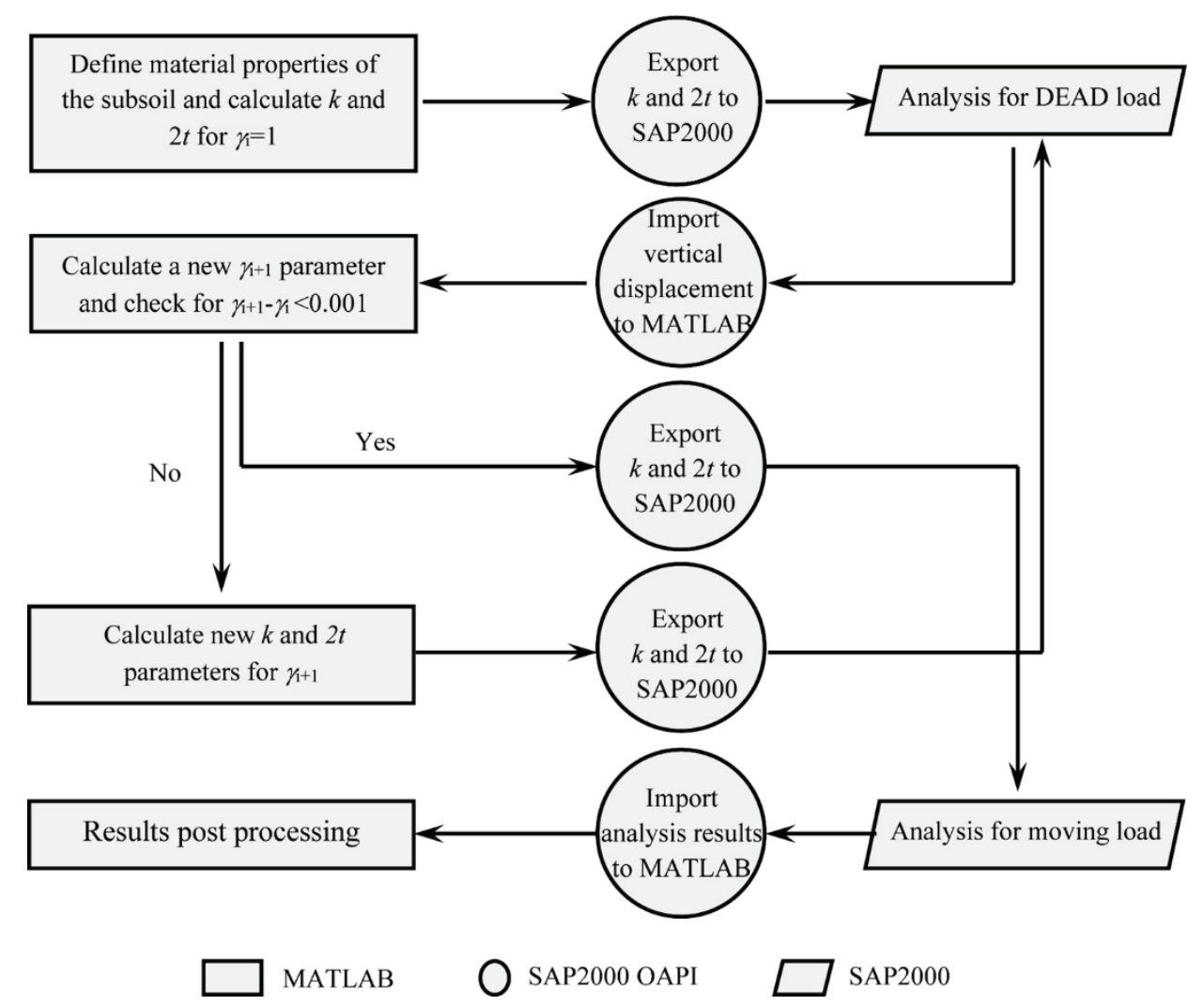

Fig.2 Flowchart for analysis of plates on elastic foundation by OAPI

\section{NUMERICAL VERIFICATION}

An orthotropic laminated beam with different boundary conditions solved by Kahya [27], Shi and Lam [28], Aydogdu [29] and Jun et al. [30] was selected to validate the presented consistent model, and non-dimensional fundamental frequencies were compared. Properties of the material used in the analysis are as follows:

$E_{1}=144.8 \times 10^{6} \mathrm{kN} / \mathrm{m}^{2}, E_{2}=9.65 \times 10^{6} \mathrm{kN} / \mathrm{m}^{2}$

$G_{12}=4.14 \times 10^{6} \mathrm{kN} / \mathrm{m}^{2}, v_{12}=0.30, \rho=1389.23 \mathrm{~kg} / \mathrm{m}^{3}$ 
Comparison of non-dimensional fundamental frequencies of laminated orthotropic beams for different boundary conditions are made in Table 1. Ratio of beam span to beam thickness $(L / h)$ was taken as 15 and non-dimensional frequency parameter was calculated with the equation $\widehat{\omega}_{1}=\omega_{1}\left(L^{2} / h\right) \sqrt{\rho / E_{1}}$. Based on the results obtained, it can be concluded that four different solutions are in good agreement with each other and the presented model provides results with sufficient accuracy.

Table 1. Nondimensional fundamental frequencies $\left(\widehat{\omega}_{1}\right)$ for various laminated beams

\begin{tabular}{|c|c|c|c|c|c|}
\hline \multirow{2}{*}{ Beam } & \multirow{2}{*}{ Ref. } & \multicolumn{4}{|c|}{ Boundary conditions } \\
\hline & & SS & $\mathrm{CC}$ & $\mathrm{CS}$ & $\mathrm{CF}$ \\
\hline \multirow[t]{5}{*}[0/90]{} & Kahya [27] & 2.4850 & 4.6011 & 3.5241 & 0.9218 \\
\hline & Shi and Lam [28] ${ }^{\mathrm{a}}$ & 2.4979 & 4.6194 & 3.5264 & 0.9199 \\
\hline & Aydogdu [29] $]^{b, c}$ & $2.5015^{\mathrm{b}}$ & 4.6531 & 3.5474 & 0.9251 \\
\hline & & $2.5036^{\mathrm{c}}$ & 4.6685 & 3.5543 & 0.9255 \\
\hline & Present study & 2.5010 & 4.5772 & 3.5179 & 0.9232 \\
\hline \multirow[t]{5}{*}[0/90/0/90]{} & Kahya [27] & 1.8329 & 3.6017 & 2.6784 & 0.6707 \\
\hline & Shi and Lam [28] & 1.9619 & 3.6994 & - & - \\
\hline & Jun et al. $[30]^{\mathrm{d}}$ & 1.9658 & 3.7086 & 2.7607 & 0.6746 \\
\hline & Present study & 1.9683 & 3.7058 & 2.7619 & 0.6751 \\
\hline & $\begin{array}{l}\text { FEM based on highe } \\
\text { Ritz method based o } \\
\text { Ritz method based o } \\
\text { Dynamic FEM base }\end{array}$ & $\begin{array}{l}\text { der beam } \\
\text { arabolic sl } \\
\text { ponential } \\
\text { first-ord }\end{array}$ & $\begin{array}{l}\text { leory } \\
\text { ar defor } \\
\text { hear def } \\
\text { beam th }\end{array}$ & $\begin{array}{l}\text { tion be } \\
\text { nation } \\
\text { ry }\end{array}$ & $\begin{array}{l}\text { heory } \\
\text { theory }\end{array}$ \\
\hline
\end{tabular}

\section{LAMINATED ORTHOTROPIC PLATES ON THREE PARAMETER ELASTIC FOUNDATION}

A parametric study was performed on a square laminated orthotropic plate resting on modified Vlasov type elastic foundation subjected to a moving concentrated load with a magnitude of $500 \mathrm{kN}$. When the load is acting on the plate, the plate makes a forced vibration motion and the motion returns to free vibration when the load leaves the plate. Dimensions of the plate are $1000 \mathrm{~mm} \times 1000 \mathrm{~mm}$. Thickness is taken as $150 \mathrm{~mm}$. Elasticity modulus of $\operatorname{subsoil}\left(E_{\mathrm{s} 1}=E_{\mathrm{s} 2}\right)$ is $68950 \mathrm{kN} / \mathrm{m}^{2}$, Poisson's ratio of the subsoil $\left(v_{\mathrm{s}}\right)$ is 0.25 and subsoil depth $\left(H_{\mathrm{s}}\right)$ under the plate is taken as $10 \mathrm{~m}$. The plate is considered to have four layers having the same thickness. The laminates are arranged by the following material properties:

$E_{1}=172.5 \times 10^{6} \mathrm{kN} / \mathrm{m}^{2}, E_{2}=6.9 \times 10^{6} \mathrm{kN} / \mathrm{m}^{2}, G_{12}=3.45 \times 10^{6} \mathrm{kN} / \mathrm{m}^{2}, v_{12}=0.25, \rho=1578 \mathrm{~kg} / \mathrm{m}^{3}$

Effects of lamination schemes

Firstly, effects of lamination scheme on the behavior of plates on elastic foundations are investigated using material and geometrical properties given above. Four different lamination schemes are examined such as $[0 / 90]_{\mathrm{s}},[0 / 90 / 0 / 90]_{\mathrm{s}},[90 / 0]_{\mathrm{s}}$, and $[45 /-45]_{\mathrm{s}}$. Soil parameters 
Modeling Laminated Orthotropic Plate-Foundation Interaction Subjected ...

evaluated for centrally concentrated static load are presented in Table 2. Moving load analysis was performed using these soil parameters. Furthermore, frequencies of the plate for each lamination scheme were calculated.

Table 2 Soil parameters for various lamination schemes

\begin{tabular}{cccc}
\hline $\begin{array}{c}\text { Lamination } \\
\text { schemes }\end{array}$ & $\gamma$ & $\begin{array}{c}k \\
\left(\mathrm{kN} / \mathrm{m}^{3}\right)\end{array}$ & $\begin{array}{c}2 t \\
(\mathrm{kN} / \mathrm{m})\end{array}$ \\
\hline$[0 / 45]_{\mathrm{s}}$ & 4.50610 & 18687.24 & 30543.18 \\
{$[0 / 90]_{\mathrm{s}}$} & 4.37260 & 18145.62 & 31459.46 \\
{$[0 / 90 / 0 / 90]$} & 4.00798 & 16679.80 & 34246.83 \\
{$[0 / 45 / 0 / 45]$} & 3.86610 & 16116.65 & 35458.20 \\
\hline
\end{tabular}

Different soil parameters were obtained for various lamination schemes. This is to be expected because the vertical displacement of plate changes depending on the lamination schemes. While subgrade reaction modulus decreases from $[0 / 45]_{\mathrm{s}}$ lamination scheme to $[0 / 45 / 0 / 45]$ lamination scheme, shear deformation parameter increases in the same order.

The first six frequencies of plate on elastic foundation are evaluated for each lamination schemes and presented in Table 3 and Fig. 3 by using soil parameters obtained above.

Table 3 First six frequencies for various lamination schemes

\begin{tabular}{ccccccc}
\hline \multirow{2}{*}{$\begin{array}{c}\text { Lamination } \\
\text { schemes }\end{array}$} & $f_{1}$ & $f_{2}$ & $f_{3}$ & $f_{4}$ & $f_{5}$ & $f_{6}$ \\
\hline$[0 / 45]_{\mathrm{s}}$ & 16.69 & 18.94 & 19.61 & 21.72 & 22.44 & 24.85 \\
{$[0 / 90]_{\mathrm{s}}$} & 16.52 & 18.90 & 19.46 & 21.66 & 22.77 & 24.71 \\
{$[0 / 90 / 0 / 90]$} & 16.05 & 18.92 & 18.92 & 21.59 & 23.85 & 23.93 \\
{$[0 / 45 / 0 / 45]$} & 15.88 & 18.56 & 18.99 & 21.53 & 22.94 & 24.30 \\
\hline
\end{tabular}

It can be seen from the table and the accompanying figure that the natural frequency increases as the mode number increases. The first and fourth frequencies decrease from $[0 / 45]_{\mathrm{s}}$ lamination scheme to $[0 / 45 / 0 / 45]$ lamination scheme. The same trend in the second and third frequency is observed. However irregular ups and downs are seen in the fifth and sixth frequencies.

Mode shapes of the plate on elastic foundation were also obtained for all lamination schemes. But since the presentation of all mode shapes would take up excessive space, only mode shapes corresponding to six lowest frequency for $[0 / 90]_{\mathrm{s}}$ are presented in Fig. 4. 


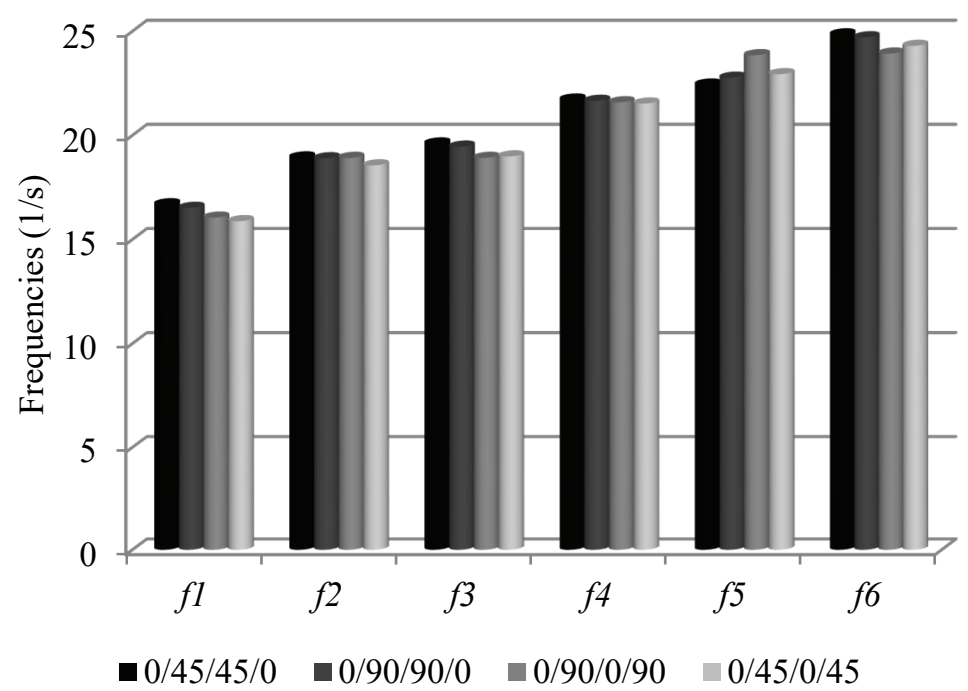

Fig.3 Comparison of first six frequencies for various lamination schemes

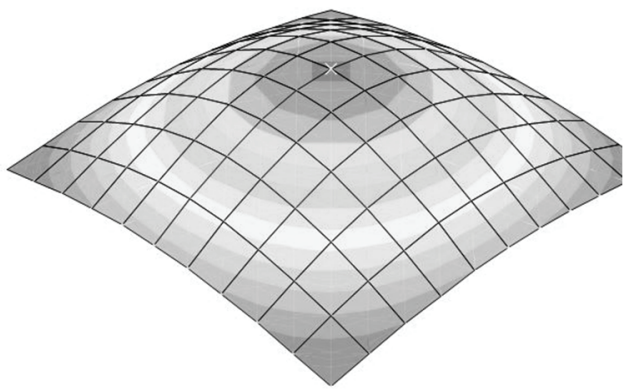

a) Mode 1

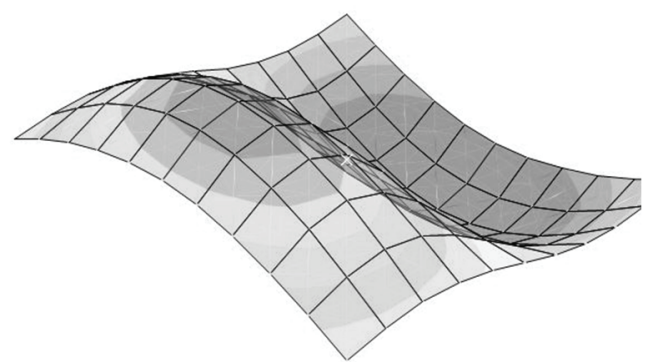

c) Mode 3

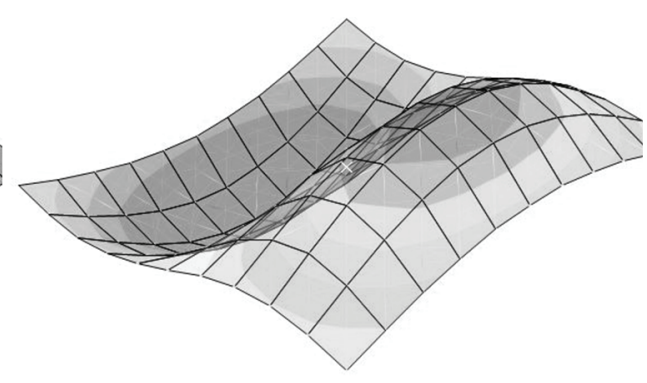

b) Mode 2

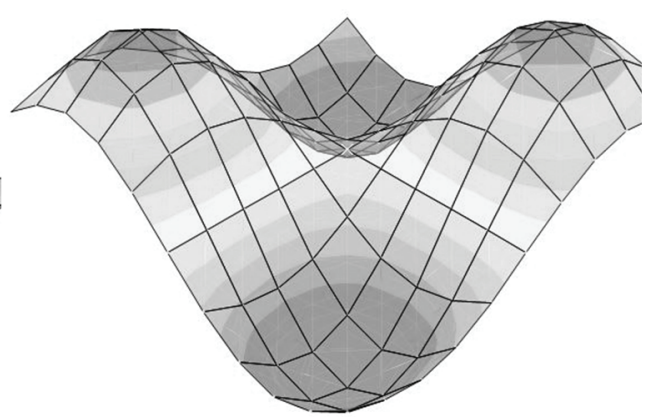

d) Mode 4 


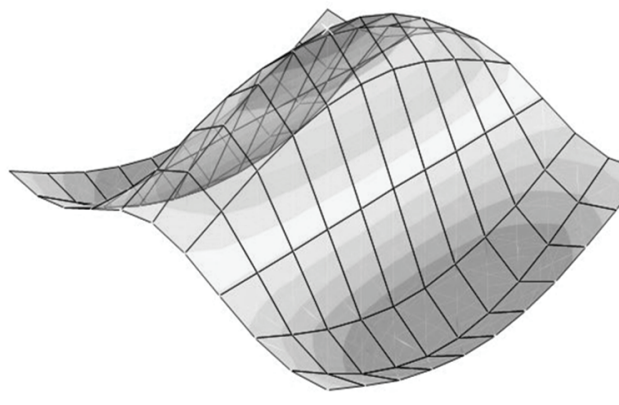

e) Mode 5

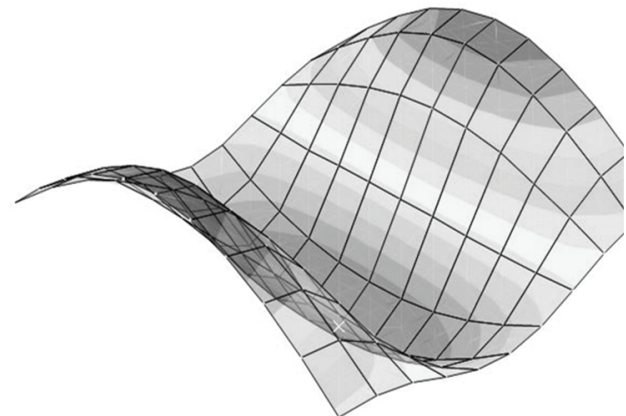

f) Mode 6

Fig. 4 First six mode shapes for [0/90] slaminated orthotropic plate on elastic foundation

Effects of moving load on the behavior of laminated orthotropic plate regarding lamination schemes were investigated considering soil-structure interaction. For the analysis, nondimensional velocity $(\alpha)$ defined as the ratio of velocity to critical velocity $\left(\alpha=c / c_{c r}\right)$ was used. The critical velocity is calculated depending on the first frequency of plate with the formulation of $c_{c r}=2 \times f_{1} \times L$. Here, the average of the first frequencies corresponding to each lamination schemes has been used as $f_{1}$ which has been taken as nearly 16.5. $\alpha=0$ indicates the state where the plate is subjected to a centrally concentrated load. Midpoint displacements obtained from the analysis are presented in Table 4 and Fig.5.

As seen from Table 4 and Fig.5, as the velocity of moving load increases, the midpoint displacement increases until the velocity reaches the value of $\alpha=0.6$, after which it decreases again. The effects of lamination schemes on the displacement of plate are seen more clearly as the load velocity increases. Midpoint displacements decrease from [0/45] lamination to [0/90/0/90] lamination for each velocity of moving load. It has also been said that the effects of the lamination scheme are more effective for the moving load as compared with the static centrally concentrated load.

\section{Effects of lamination angles $(0 / \theta / \theta / 0)$}

Here, the influence of lamination angles on the behavior of the plate was investigated. For this purpose, a four-layer plate was considered. Each layer has equal thickness. Angles of top and bottom layer are kept at $0^{\circ}$ and middle layers are changed as $0^{\circ}, 30^{\circ}, 45^{\circ}, 60^{\circ}$ and $90^{\circ}$. Soil parameters obtained for various lamination angles are given in Table 5.

As middle lamination angle $(\theta)$ increases, modulus of subgrade reaction decreases and shear deformation parameter increases.

The first six frequencies of plate on elastic foundation are presented in Fig.6 using these soil parameters. As seen from the figure, the first four frequencies of the plate tend to decrease as lamination angle $(\theta)$ increases. Furthermore, effects of lamination angles on the frequencies of plate decrease for the frequencies corresponding to large modes. 
Table 4 Midpoint vertical displacement of plate for various lamination schemes

\begin{tabular}{ccccccc}
\hline \multirow{2}{*}{$\begin{array}{c}\text { Lamination } \\
\text { schemes }\end{array}$} & $\alpha=0.0$ & $\alpha=0.2$ & $\alpha=0.4$ & $\alpha=0.6$ & $\alpha=0.8$ & $\alpha=1.0$ \\
\hline \cline { 2 - 7 } & 2.59 & 3.04 & 4.02 & 4.76 & 4.38 & 3.43 \\
\hline$[0 / 45]_{\mathrm{s}}$ & 2.48 & 2.80 & 3.93 & 4.46 & 4.12 & 3.16 \\
{$[0 / 90]_{\mathrm{s}}$} & 2.47 & 2.59 & 3.91 & 4.46 & 3.77 & 2.93 \\
{$[0 / 45 / 0 / 45]$} & 2.93 & & \\
{$[0 / 90 / 0 / 90]$} & 2.34 & 2.53 & 3.86 & 4.03 & 3.49 & 2.57 \\
\hline
\end{tabular}

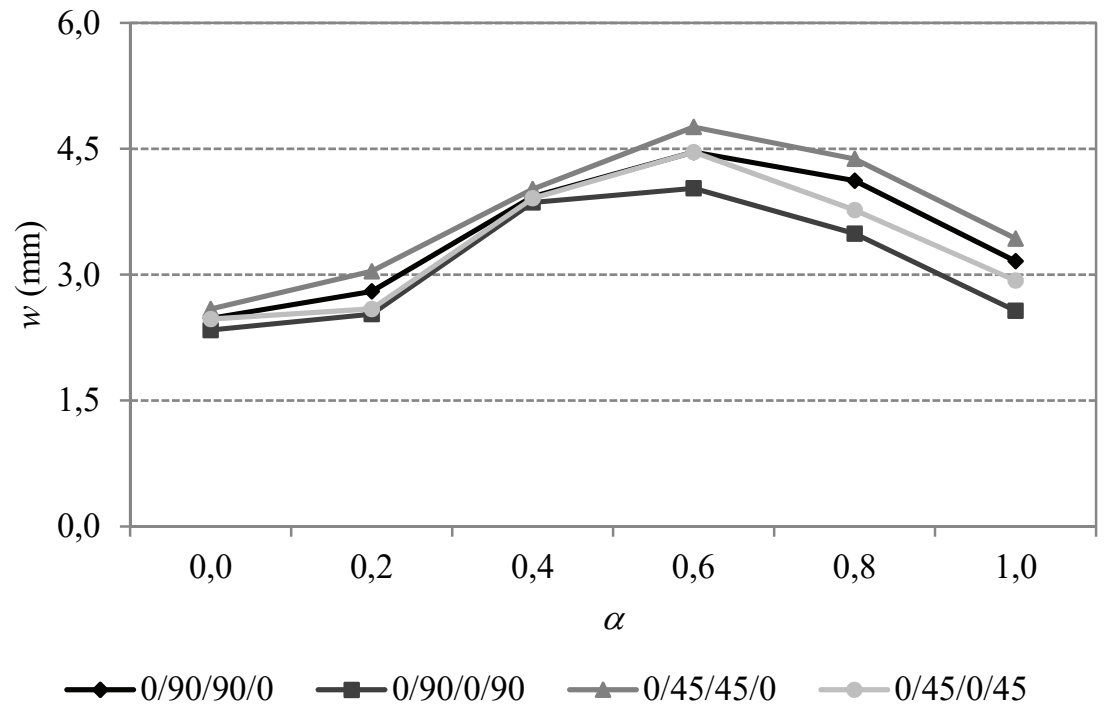

Fig.5 Comparison of midpoint displacement of plate for various lamination schemes

Table 5 Soil parameters for various lamination angles $(0 / \theta / \theta / 0)$

\begin{tabular}{cccc}
\hline $\begin{array}{c}\text { Lamination } \\
\text { schemes }\end{array}$ & $\gamma$ & $\begin{array}{c}k \\
\left(\mathrm{kN} / \mathrm{m}^{3}\right)\end{array}$ & $\begin{array}{c}2 t \\
(\mathrm{kN} / \mathrm{m})\end{array}$ \\
\hline$[0 / 0]_{\mathrm{s}}$ & 5.09986 & 21115.69 & 27021.45 \\
{$[0 / 30]_{\mathrm{s}}$} & 4.74592 & 19664.96 & 29019.29 \\
{$[0 / 45]_{\mathrm{s}}$} & 4.50610 & 18687.24 & 30543.18 \\
{$[0 / 60]_{\mathrm{s}}$} & 4.34213 & 18022.29 & 31675.97 \\
{$[0 / 90]_{\mathrm{s}}$} & 4.37226 & 18145.62 & 31459.46 \\
\hline
\end{tabular}


Modeling Laminated Orthotropic Plate-Foundation Interaction Subjected ...

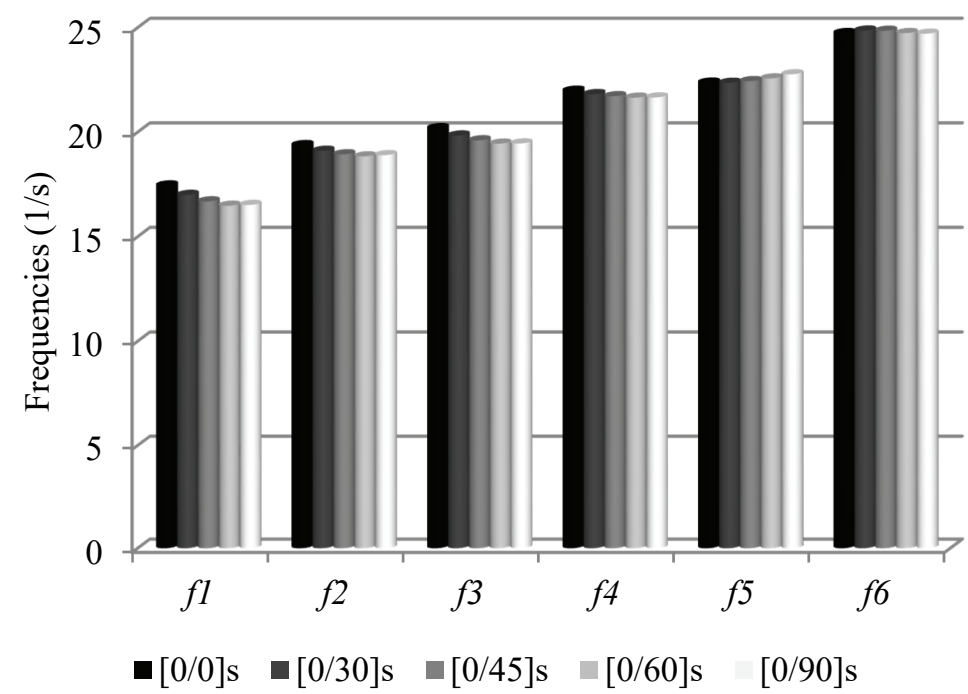

Fig.6 Comparison of first six frequencies for various lamination angles

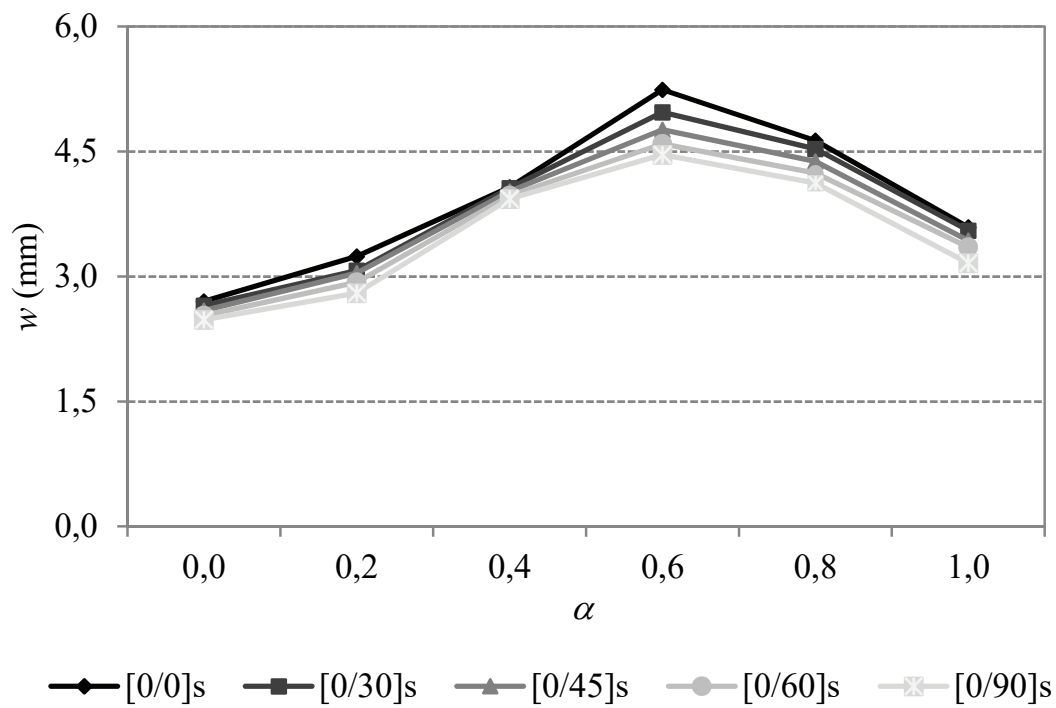

Fig.7 Comparison of midpoint displacement of plate for various lamination angles

Midpoint displacement of the plate for various lamination angles is plotted in Fig.7. The smallest vertical displacement is obtained for $[0 / 90]_{\mathrm{s}}$ in comparison to other lamination 
schemes. The displacement increases with decreasing middle lamination angle $(\theta)$ for all non-dimensional velocities of moving load. The largest value of midpoint displacement is obtained for $\alpha=0.6$ as before. The lamination angles effect on the displacement for $\alpha=0.6$ is much higher than that of other non-dimensional velocities. Further, displacement order for various lamination angles considered is as follows $[0 / 0]_{\mathrm{s}}>[0 / 30]_{\mathrm{s}}>[0 / 45]_{\mathrm{s}}>[0 / 60]_{\mathrm{s}}>$ $[0 / 90]_{\mathrm{s}}$.

\section{Effects of layer number}

Here, keeping the plate thickness constant, the plate is considered as 3-layered, 4-layered, 5layered and 6-layered to demonstrate the effects of number of layers on the behavior of the plate. Table 6 shows that modulus of subgrade reaction decreases with increasing number of layers. But, shear deformation parameter increases as the number of layer increases.

Table 6 Soil parameters for various layer numbers

\begin{tabular}{cccc}
\hline $\begin{array}{c}\text { Lamination } \\
\text { schemes }\end{array}$ & $\gamma$ & $\begin{array}{c}k \\
\left(\mathrm{kN} / \mathrm{m}^{3}\right)\end{array}$ & $\begin{array}{c}2 t \\
(\mathrm{kN} / \mathrm{m})\end{array}$ \\
\hline$[0 / 90 / 0]$ & 4.75291 & 19693.56 & 28977.04 \\
{$[0 / 90]_{\mathrm{s}}$} & 4.37226 & 18145.62 & 31459.46 \\
{$[0 / 90 / 0 / 90 / 0]$} & 4.19780 & 17440.05 & 32740.72 \\
{$[0 / 90 / 0]_{\mathrm{s}}$} & 4.12921 & 17164.52 & 33270.57 \\
\hline
\end{tabular}

Fig. 8 displays the variation of first six frequencies with the numbers of layers of the plate. Frequencies decrease from 3-layered plate to 6-layered plate except for fifth frequencies.

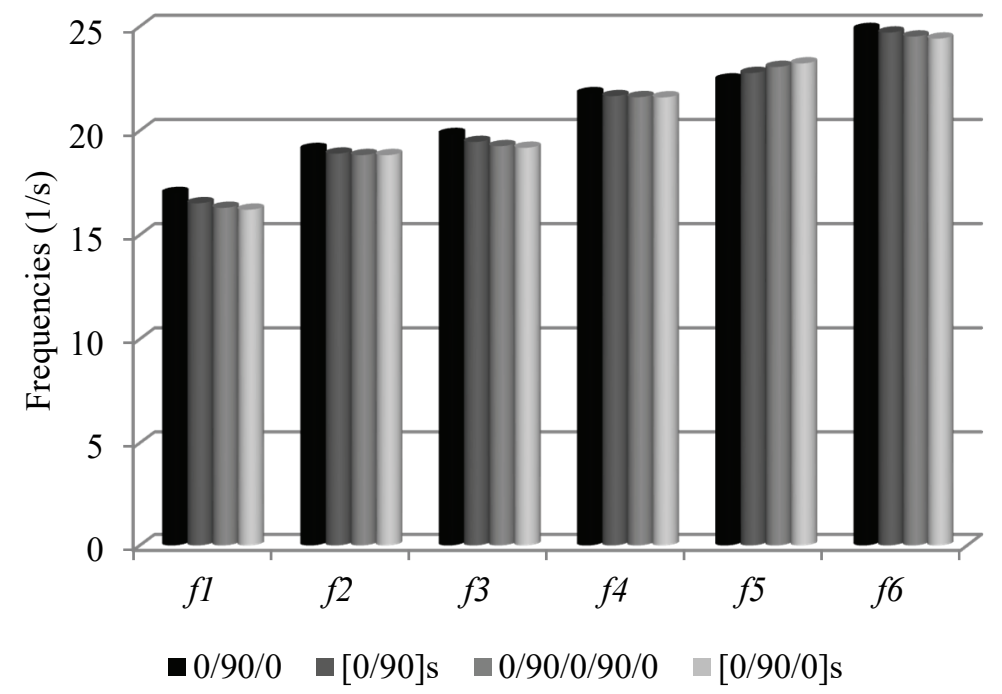

Fig.8 Comparison of first six frequencies for various layer numbers 
Modeling Laminated Orthotropic Plate-Foundation Interaction Subjected ...

Midpoint displacements(w) of the plate for various layer numbers are plotted in Fig.9. It is also seen that the central displacement increases up to $\alpha=0.6$ and decreases for the larger values of $\alpha$. It is also observed that the curves approach each other as the number of layers increases. So, it can be said that an increase in the number of layers does not cause any significant change on the results beyond a certain value.

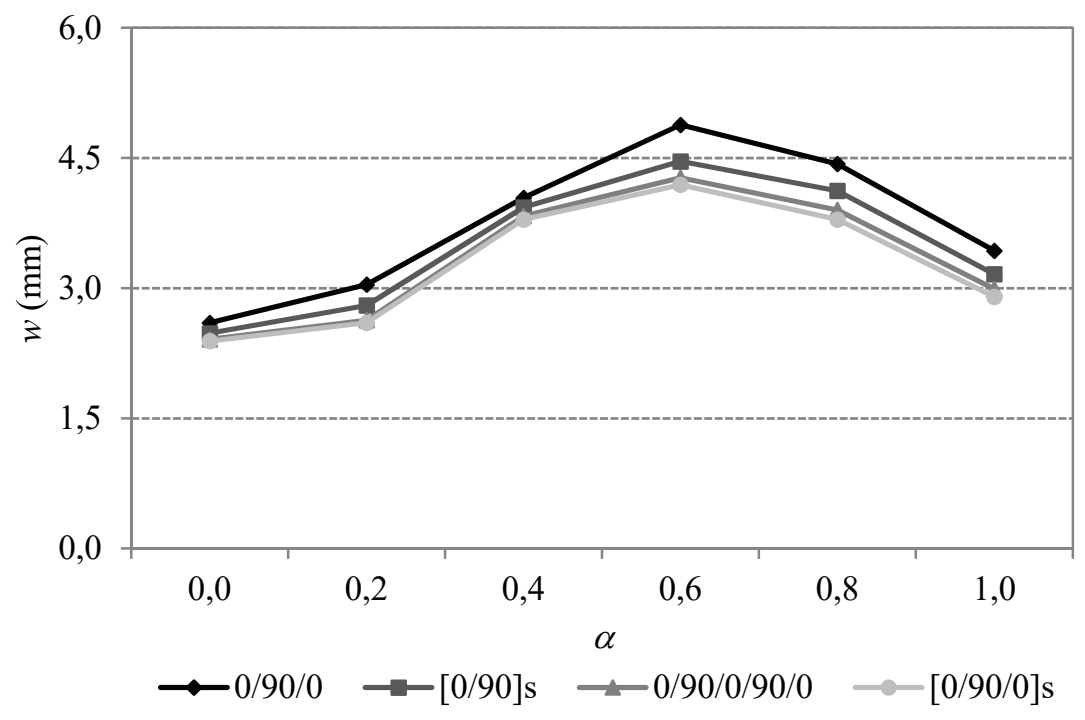

Fig. 9 Comparison of midpoint displacement of plate for various lamination numbers

\section{Effects of subsoil depth}

The plate on elastic foundation with $[0 / 90]_{\mathrm{s}}$ lamination is chosen to indicate the effects of subsoil depth on the responses. Analyses were performed for five different subsoil depths of 2, 4, 6, 8 and $10 \mathrm{~m}$. Soil parameters under a central concentrated load are tabulated in Table 7. As the subsoil depth increases, subgrade reaction modulus decreases while shear deformation modulus increases because deeper rigid base makes soil stratum more flexible.

Table 7 Soil parameters for various subsoil depth

\begin{tabular}{cccc}
\hline $\begin{array}{c}\text { Subsoil } \\
\text { Depth }(\mathrm{m})\end{array}$ & $\gamma$ & $\begin{array}{c}k \\
\left(\mathrm{kN} / \mathrm{m}^{3}\right)\end{array}$ & $\begin{array}{c}2 t \\
(\mathrm{kN} / \mathrm{m})\end{array}$ \\
\hline 2 & 1.16488 & 42700.44 & 15605.36 \\
4 & 1.94472 & 24289.08 & 24844.61 \\
6 & 2.70872 & 19749.34 & 29336.09 \\
8 & 3.25181 & 18468.33 & 30993.67 \\
10 & 4.37226 & 18145.62 & 31459.46 \\
\hline
\end{tabular}


Frequencies of the plate on elastic foundation are plotted in Fig.10. As seen from the figure, frequencies of the plate decrease when soil stratum is more flexible. But changes in the frequencies decrease with increasing subsoil depth. This means that subsoil depth does not affect the frequencies considerably after a certain value of subsoil depth.

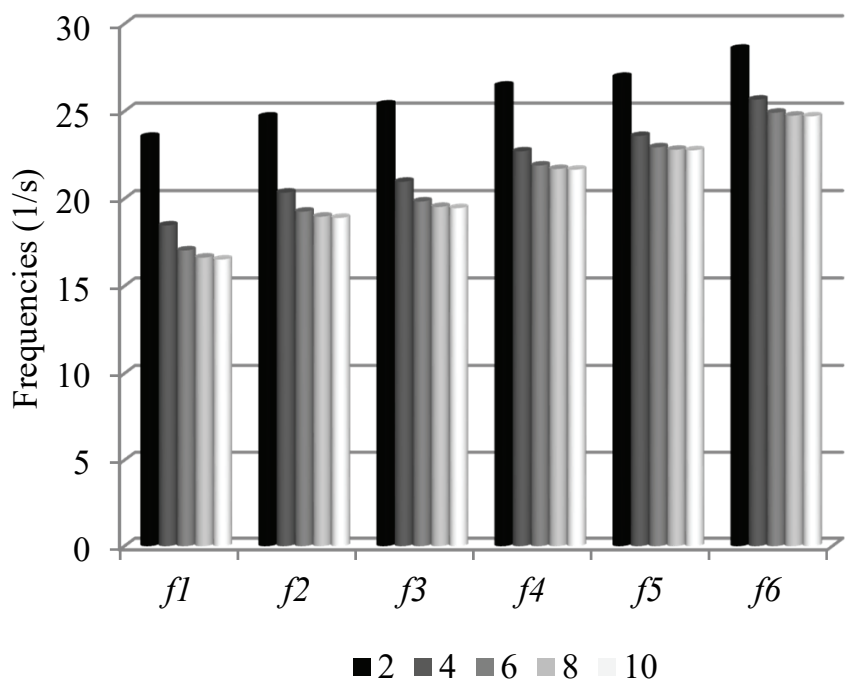

Fig.10 Comparison of first six frequencies for various subsoil depth

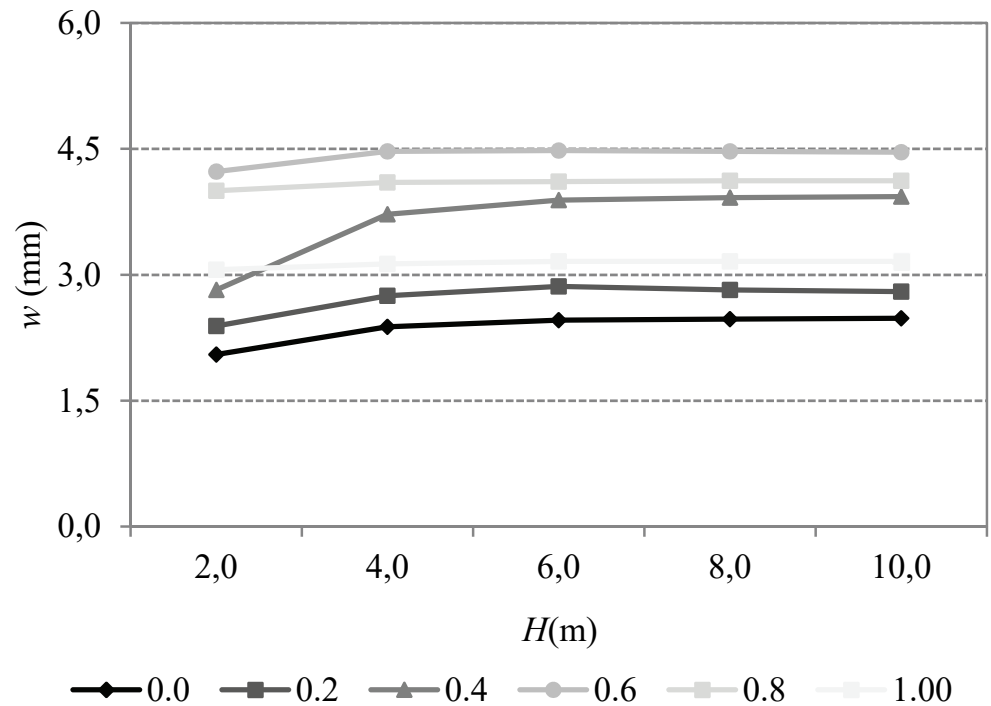

Fig.11 Comparison of central displacement of plate for various subsoil depth 
Modeling Laminated Orthotropic Plate-Foundation Interaction Subjected ...

It is observed that the central displacement is maximum for $H=10 \mathrm{~m}$, and minimum for $H=2$ $\mathrm{m}$. That is because, as the depth of the soil stratum decreases, the central displacement decreases as well. The displacement increases with the decreasing modulus of subgrade reaction and increasing shear deformation parameter. All these findings suggest that the effects of soil parameters on the displacement are quite significant but the same cannot be claimed for the soil depth. Studying Fig.11, it is easy to see that the effect of subsoil depth on the plate displacement vanishes as the soil gets deeper. This means that subsoil depth does not affect the results considerably after a certain value; namely $6 \mathrm{~m}$ for $\alpha=0.0,0.2$ and $0.4,4$ $\mathrm{m}$ for $\alpha=0.6$ and, $2 \mathrm{~m}$ for $\alpha=0.8$ and 1.0 .

\section{Effects of subsoil elasticity modulus}

Various values of subsoil modulus of elasticity at the bottom have been considered to display the effects of changes of subsoil elasticity modulus through the depth on the behavior of plate for $[0 / 90]_{\mathrm{s}}$ lamination schemes. Subsoil elasticity modulus at the bottom, $E_{\mathrm{s} 2}$, was changed for the ratios of $E_{\mathrm{s} 2} / E_{\mathrm{s} 1}=1,2,3$ and 4 , keeping subsoil elasticity modulus at the top constant at $E_{\mathrm{s} 1}=68950 \mathrm{kN} / \mathrm{m}^{2}$. Table 8 demonstrates soil parameters for various ratio of $E_{\mathrm{s} 2} / E_{\mathrm{s} 1}$. Table 8 shows that the subgrade reaction modulus increases while shear deformation parameter decreases as the ratio of $E_{\mathrm{s} 2} / E_{\mathrm{s} 1}$ increases that is, as the subsoil becomes stiffer.

Table 8 Soil parameters for various ratio of bottom to top elasticity modulus of subsoil

\begin{tabular}{cccc}
\hline$E_{\mathrm{s} 2} / E_{\mathrm{s} 1}$ & $\gamma$ & $\begin{array}{c}k \\
\left(\mathrm{kN} / \mathrm{m}^{3}\right)\end{array}$ & $\begin{array}{c}2 t \\
(\mathrm{kN} / \mathrm{m})\end{array}$ \\
\hline 1 & 4.37226 & 18145.62 & 31459.46 \\
2 & 4.52411 & 20848.92 & 33759.70 \\
3 & 4.65731 & 23472.46 & 35872.88 \\
4 & 4.77701 & 26037.75 & 37838.20 \\
\hline
\end{tabular}

Comparison of the first six frequencies for various ratios of $E_{\mathrm{s} 2} / E_{\mathrm{s} 1}$ is presented in Fig.12. It is seen that all frequencies increase with the increasing ratio of $E_{\mathrm{s} 2} / E_{\mathrm{s} 1}$ and the increases are quite similar for the frequencies corresponding to the first six modes.

Comparison of the midpoint displacement of plate for various ratios of $E s_{2} / E s_{1}$ is given in Fig.13. Results show that the central displacements of the plate decrease as the subsoil elasticity modulus at the bottom increases. As the foundation becomes stiffer by increasing the subsoil elasticity modulus at the bottom, the midpoint displacement of the plate continues to drop. But the effects of subsoil elasticity modulus on the displacement of the plate loses its importance for a large velocity moving load, especially for $\alpha=0.8$.

\section{Effects of plate thickness}

Herein, effects of the plate thickness on the behavior of plate are investigated. For this purpose, the various thickness to length ratio is used taking $h / L=0.015,0.030,0.045$ and 0.060 keeping the span of plate constant at $10 \mathrm{~m}$. The plate has 4 layers of equal thickness and its lamination scheme is $[0 / 90]_{\mathrm{s}}$. It is seen from Table 9 that subgrade reaction modulus decreases while shear deformation modulus increases as $h / L$ ratio increases. 
Korhan ÖZGAN

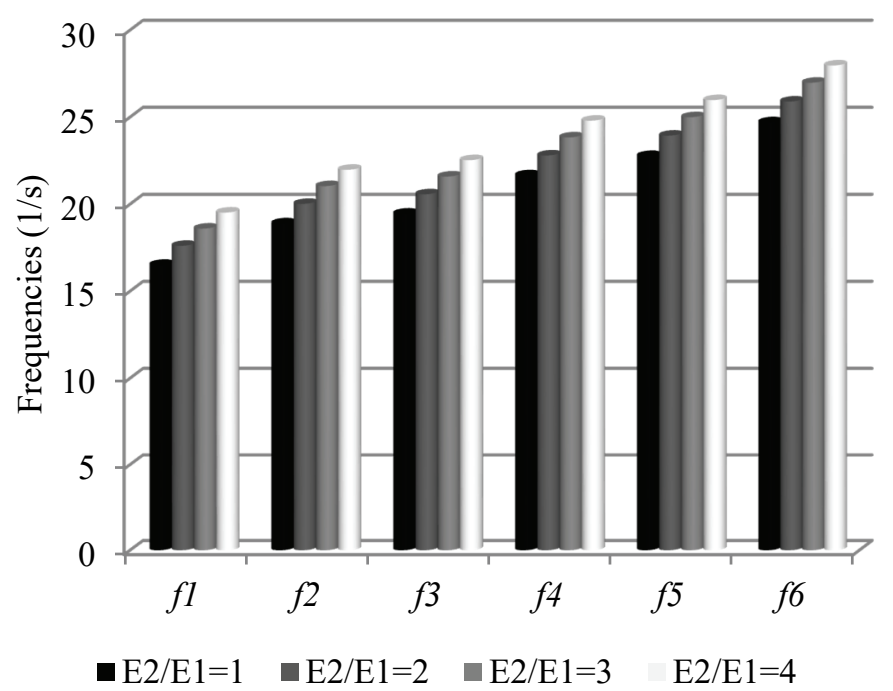

Fig.12 Comparison of first six frequencies for various ratio of bottom to top elasticity modulus of subsoil

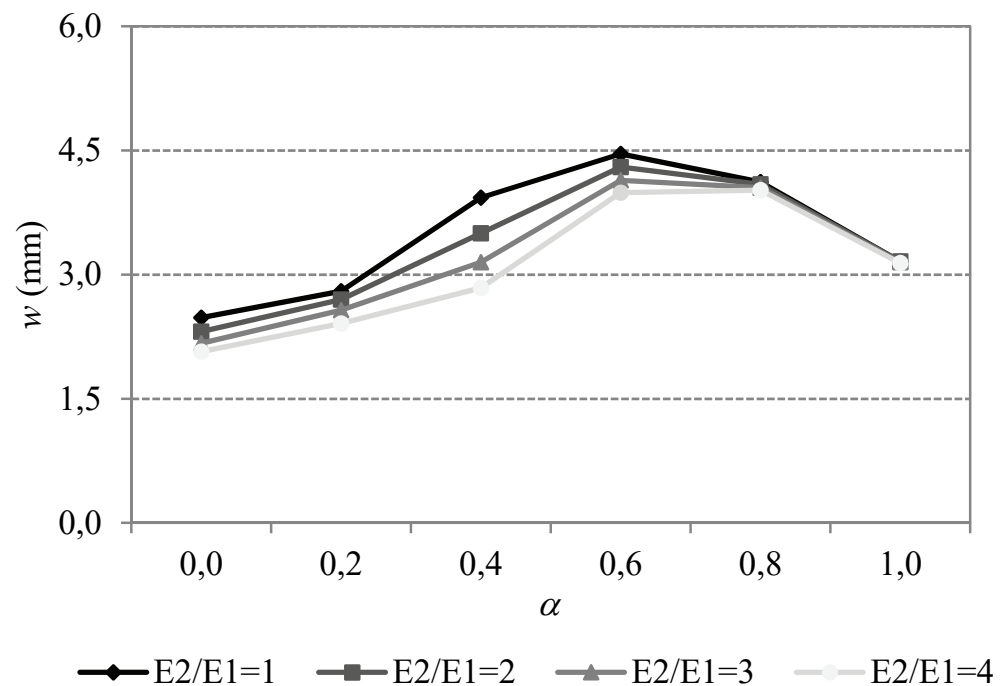

Fig.13 Comparison of midpoint displacement of plate for various ratio of $E_{2} / E_{1}$ 
Modeling Laminated Orthotropic Plate-Foundation Interaction Subjected ...

Table 9 Soil parameters for various plate thicknesses

\begin{tabular}{ccrc}
\hline$h / L$ & $\gamma$ & $\begin{array}{c}k \\
\left(\mathrm{kN} / \mathrm{m}^{3}\right)\end{array}$ & $\begin{array}{c}2 t \\
(\mathrm{kN} / \mathrm{m})\end{array}$ \\
\hline 0.015 & 4.37226 & 18145.62 & 31459.46 \\
0.030 & 2.57224 & 11412.20 & 50985.25 \\
0.045 & 1.96482 & 9760.53 & 61719.86 \\
0.060 & 1.65983 & 9156.86 & 67841.71 \\
\hline
\end{tabular}

Fig.14 demonstrates comparison of first six frequencies for various plate thicknesses. Frequencies decrease with increasing plate thickness. But the drops in the frequencies for large values of plate thickness are less.

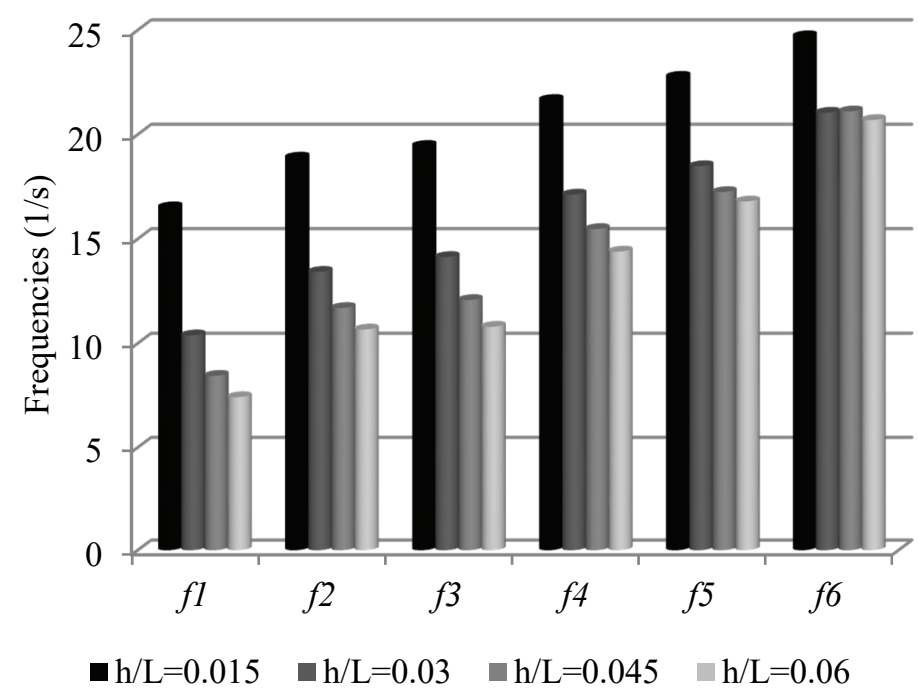

Fig.14 Comparison of first six frequencies for various plate thicknesses

As seen from Fig.15, displacements decrease with increasing plate thickness. This is because bending rigidity of the plate increases as the plate thickness increases hence, the decrease in vertical displacement of the plate. It can also be observed that for large values of the ratio $h / L$, the midpoint displacement does not vary significantly. Furthermore, the effect of plate thickness on the displacement of plate is lost after a certain value of plate thickness. 


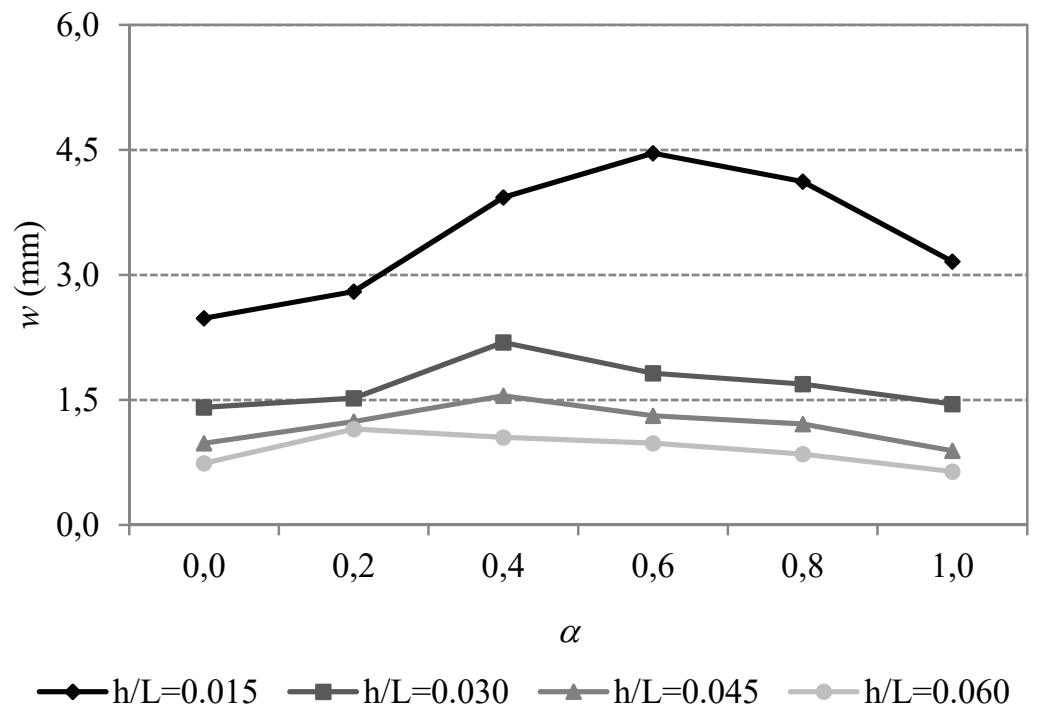

Fig.15 Comparison of midpoint displacement of plate for various plate thicknesses

The variation of midpoint displacement with non-dimensional time for 0/90/90/0 symmetric laminated plate and various velocities of moving load and for various laminated plates and $\alpha=0.6$ values are shown at Fig. $16 \mathrm{a}$ and Fig. $16 \mathrm{~b}$.

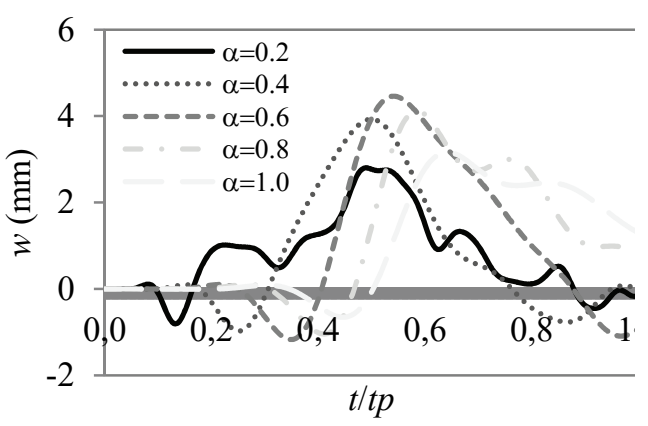

a)

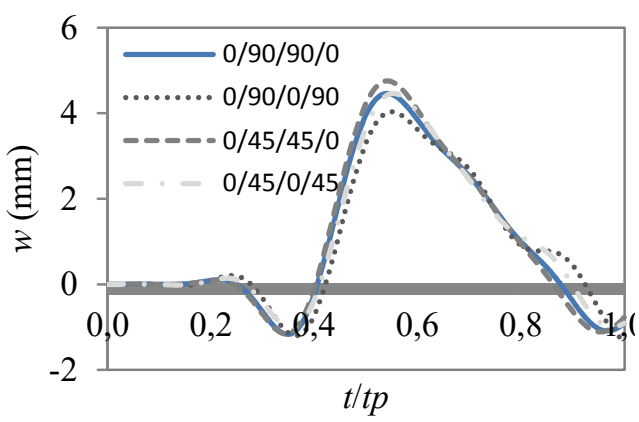

b)

Fig.16 Variation of midpoint displacement with non-dimensional time

\section{CONCLUSIONS}

In this study, the behavior of laminated orthotropic plates on an elastic foundation subjected to moving load was studied using the modified Vlasov model. For this purpose, a computer 
Modeling Laminated Orthotropic Plate-Foundation Interaction Subjected ...

tool was developed to make two-way data exchange between SAP2000 and MATLAB using OAPI functions. First the accuracy of the proposed model was verified and the effects of the lamination scheme, various lamination angles, lamination number, subsoil depth, elasticity modulus of subsoil, plate thickness and velocity of moving load on the behavior of laminated orthotropic plates on elastic foundation were discussed. The conclusions drawn from the study are summarized below.

- The results from the solution procedure presented in the study show good agreement with those of the numerical analyses in the literature. The solution procedure may be effectively used for the analysis of laminated composite plates on elastic foundations. The main advantage of the solution procedure developed is that it is a powerful tool to handle and solve various situations with various boundary conditions, orientation angles, lamination schemes and load types.

- Plate thickness, subsoil depth and elasticity modulus have important influence on the behavior of the plate.

- Midpoint displacement of the plate for all lamination schemes increases as the velocity of moving load increases up to a certain value. The displacements decrease with increasing velocity of the moving load.

- The effects of lamination schemes on the displacement of plate are seen more clearly as the load velocity increases.

- The effect of the layer number on the results decreases as the number of layers increases.

- Subsoil depth does not affect the results considerably after a certain value.

- The effect of subsoil elasticity modulus on the results loses its importance for large velocities of moving load.

- The effect of the plate thickness on the results decreases as the thickness of plate increases.

\section{References}

[1] Kim, S.M., Roesset, J.M., Moving loads on a plate on elastic foundation. Journal of Engineering Mechanics-Asce. 124(9), 1010-1017, 1998.

[2] Huang, M.H., Thambiratnam, D.P., Dynamic response of plates on elastic foundation to moving loads. Journal of Engineering Mechanics. 128(9, 1016-1022, 2002.

[3] Kim, S.M., Buckling and vibration of a plate on elastic foundation subjected to in-plane compression and moving loads. International Journal of Solids and Structures. 41(20), 5647-5661, 2004.

[4] Lu, Z., Yao, H.L., Zhan, Y.X., Hu, Z., Vibrations of a plate on a two-parameter foundation subjected to moving rectangular loads of varying velocities. Journal of Vibroengineering. 16(3), 1543-1554, 2014. 
[5] Wang, X.D., Numerical analysis of moving orthotropic thin plates. Computers \& Structures. 70(4), 467-486, 1999.

[6] Zhu, X.Q., Law, S.S., Dynamic behavior of orthotropic rectangular plates under moving loads. Journal of Engineering Mechanics-Asce. 129(1), 79-87, 2003.

[7] Alisjahbana, S.W., Dynamic Response of Clamped Orthotropic Plates to Dynamic Moving Loads in $13^{\text {th }}$ World Conference on Earthquake Engineering. Vancouver, B.C., Canada, 2004.

[8] Lee, S.Y., Yhim, S.S., Dynamic analysis of composite plates subjected to multi-moving loads based on a third order theory. International Journal of Solids and Structures. 41(16-17), 4457-4472, 2004.

[9] Law, S.S., Bu, J.Q., Zhu, X.Q., Chan, S.L., Moving load identification on a simply supported orthotropic plate. International Journal of Mechanical Sciences. 49(11), 1262-1275, 2007.

[10] Hatami, S., Azhari, M., Saadatpour M.M., Free vibration of moving laminated composite plates. Composite Structures. 80(4), 609-620, 2007.

[11] Ghafoori, E., Asghari, M., Dynamic analysis of laminated composite plates traversed by a moving mass based on a first-order theory. Composite Structures. 92(8), 18651876, 2010.

[12] Malekzadeh, P., Fiouz A.R., Razi, H., Three-dimensional dynamic analysis of laminated composite plates subjected to moving load. Composite Structures. 90(2), 105-114, 2009.

[13] Thai, C.H., Nguyen-Xuan, H., Nguyen-Thanh, N., Le, T.H., Nguyen-Thoi, T., Rabczuk T., Static, free vibration, and buckling analysis of laminated composite ReissnerMindlin plates using NURBS-based isogeometric approach. International Journal for Numerical Methods in Engineering. 91(6), 571-603, 2012.

[14] Chen, C.S., Tsai, T.C., Chen, W.R., Wei, C.L., Dynamic stability analysis of laminated composite plates in thermal environments. Steel and Composite Structures. 15(1), 5779, 2013.

[15] Patel, S.N., Nonlinear bending analysis of laminated composite stiffened plates. Steel and Composite Structures. 17(6), 867-890, 2014.

[16] Ozcelikors, Y., Omurtag, M.H., Demir, H., Analysis of orthotropic plate-foundation interaction by mixed finite element formulation using Gateaux differential. Computers \& Structures. 62(1), 93-106, 1997.

[17] Pradhan, S.C., Kumar, A., Vibration analysis of orthotropic graphene sheets embedded in Pasternak elastic medium using nonlocal elasticity theory and differential quadrature method. Computational Materials Science. 50(1), 239-245, 2010.

[18] Akgoz, B., Civalek, O., Nonlinear vibration analysis of laminated plates resting on nonlinear two-parameters elastic foundations. Steel and Composite Structures. 11(5), 403-421, 2011. 
Modeling Laminated Orthotropic Plate-Foundation Interaction Subjected ...

[19] Vosoughi, A.R., Malekzadeh, P., Razi, H., Response of moderately thick laminated composite plates on elastic foundation subjected to moving load. Composite Structures. 97, 286-295, 2013.

[20] Afsharmanesh, B., Ghaheri, A., Taheri-Behrooz, T., Buckling and vibration of laminated composite circular plate on winkler-type foundation. Steel and Composite Structures. 17(1), 1-19, 2014.

[21] Mantari, J.L., Granados, E.V., Hinostroza, M.A., Soares, C.G., Modelling advanced composite plates resting on elastic foundation by using a quasi-3D hybrid type HSDT. Composite Structures. 118, 455-471, 2014.

[22] Alipour, M.M., An analytical approach for bending and stress analysis of cross/angleply laminated composite plates under arbitrary non-uniform loads and elastic foundations. Archives of Civil and Mechanical Engineering. 16(2), 193-210, 2016.

[23] SAP2000, Integrated Finite Elements Analysis and Design of Structures. Computers and Structures. p. Inc, Berkeley, CA, 2008.

[24] MATLAB, The language of technical computing. The Mathworks. p. Natick, MA, 2009.

[25] Humar. J.L., Dynamic of Structures, Englewood Cliffs, NJ, Prentice-Hall, 1990.

[26] Vallabhan, C.V.G., Straughan, W.T., Das, Y.C., Refined Model for Analysis of Plates on Elastic Foundations. Journal of Engineering Mechanics-Asce. 117(12), 2830-2844, 1991.

[27] Kahya, V., Dynamic analysis of laminated composite beams under moving loads using finite element method. Nuclear Engineering and Design. 243, 41-48, 2012.

[28] Shi, G., Lam, K.Y., Finite element vibration analysis of composite beams based on higher-order beam theory. Journal of Sound and Vibration. 219(4), 707-721, 1999.

[29] Aydogdu, M., Vibration analysis of cross-ply laminated beams with general boundary conditions by Ritz method. International Journal of Mechanical Sciences. 47(11), 1740$1755,2005$.

[30] Jun, L.H., H.; Rongying, S., Dynamic finite element method for generally laminated composite beams. International Journal of Mechanical Sciences. 50, 466-480, 2008. 